\title{
COVID-19 fears may widen gaps in early pregnancy care
}

\author{
C Cite as: CMAJ 2020 July 27;192:E870. doi: 10.1503/cmaj.1095885
}

Posted on cmajnews.com on July 10, 2020

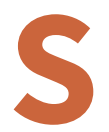

ome doctors are concerned that pregnant patients are risking lifethreatening complications by avoiding the emergency department due to coronavirus disease 2019 (COVID-19) fears.

Normally, one in three pregnant women in Ontario will use the emergency department at some time during their pregnancy, most often during the first 12 weeks when they may not have an obstetrician. And about $80 \%$ of women who experience a miscarriage or threatened miscarriage will seek emergency care.

With COVID-19 making access to obstetric care more complicated, one might expect to see a spike in emergency department visits. But some Toronto doctors say they're seeing fewer pregnant patients in the emergency department during the pandemic, leading them to suspect that some women may be delaying or avoiding care.

"All patients are hesitant to attend hospitals right now," says Dr. Catherine Varner, an emergency physician at Mount Sinai Hospital. "Emergency department volumes are down across Ontario."

Varner is particularly concerned for women in the early stages of pregnancy, who often rely on a patchwork of family doctors, walk-in clinics and emergency departments for care. "There is already not a lot of infrastructure for early pregnancy complications and miscarriage," she says.

Early pregnancy complications can be "an incredibly isolating and daunting experience to go through in the best of times," says patient advocate Kristin Blakely. She found it difficult to access the information and care she needed when she experienced multiple miscarriages.

Those gaps are surely "compounded now by the uncertainties with COVID-19 in

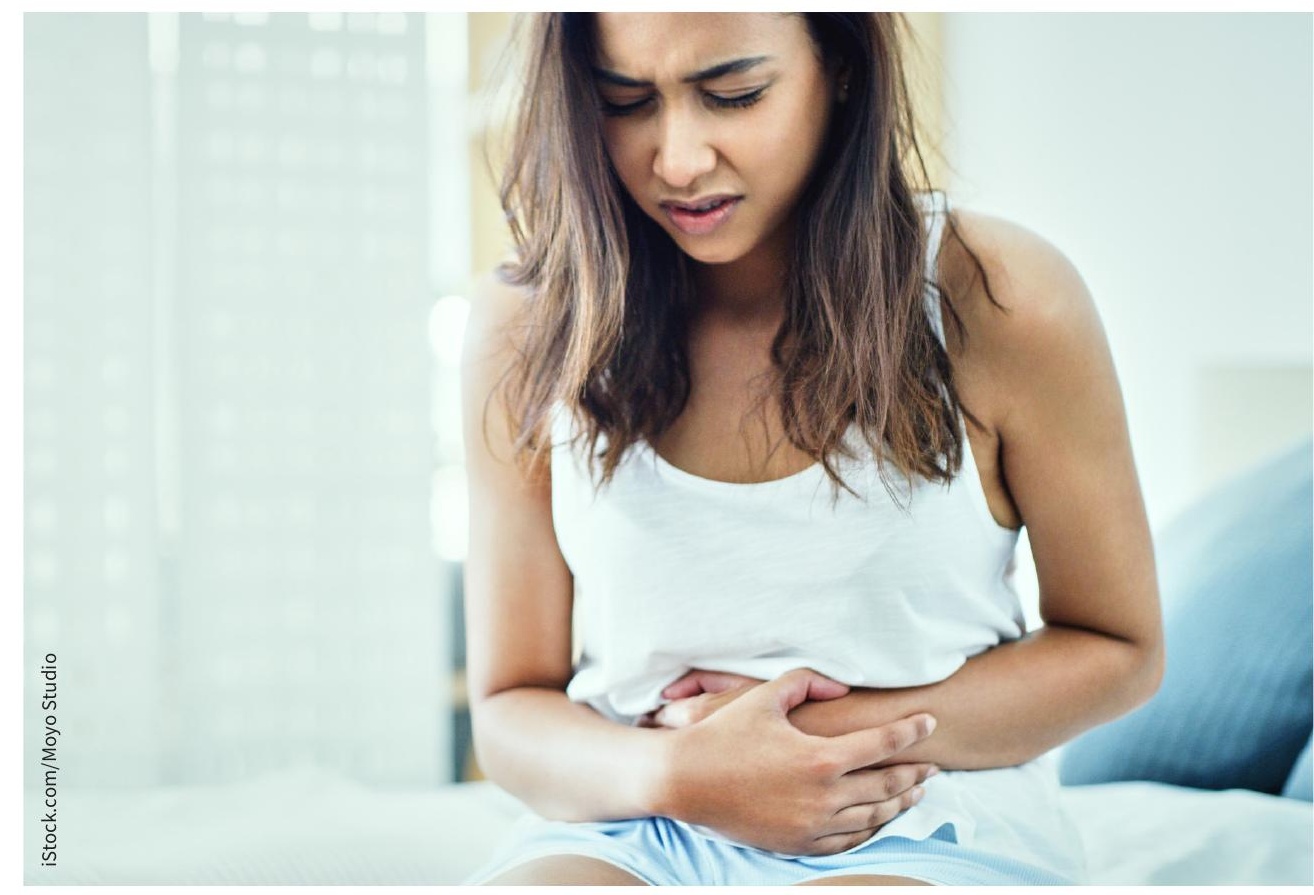

Some women may be delaying or avoiding care for early pregnancy complications.

terms of where to go, how to have your questions answered and health care needs met," she says.

Although many women may miscarry at home without complications, symptoms like heavy bleeding and abdominal pain could indicate an ectopic pregnancy, in which a fertilized egg attaches outside of the uterus. Some $1-2 \%$ of all pregnancies in North America are ectopic and may require surgery to prevent life-threatening internal bleeding.

"It is difficult to tell the difference between an ectopic pregnancy and a miscarriage, which is why these are the patients we are really worried about," says Varner. "We want everyone to be confident that the emergency department is safe."

Later stage miscarriages may also require a dilation and curettage, or $D \& C$, to remove remaining products of conception in the uterus.

Dr. Jackie Thomas, director of the early pregnancy clinic at Mount Sinai, recently encountered a woman who presented to the emergency department with a "serious infection in her uterus because she was too scared to book a D\&C" following a miscarriage. "The fear of not coming into a hospital for crucial care is dangerous," Thomas says.

During the pandemic, the clinic has provided telephone advice to women miscarrying at home. "We are doing things virtually as much as possible," Thomas says. However, "some things cannot be done virtually, [such as] when patients need an exam, blood work or a D\&C."

Natasha Comeau, Toronto, Ont. 